This item was submitted to Loughborough's Research Repository by the author.

Items in Figshare are protected by copyright, with all rights reserved, unless otherwise indicated.

\title{
Employer's management of employees affected by cancer
}

PLEASE CITE THE PUBLISHED VERSION

https://doi.org/10.1007/s00520-017-3998-8

\section{PUBLISHER}

(C) Springer

\section{VERSION}

AM (Accepted Manuscript)

\section{PUBLISHER STATEMENT}

This work is made available according to the conditions of the Creative Commons Attribution-NonCommercialNoDerivatives 4.0 International (CC BY-NC-ND 4.0) licence. Full details of this licence are available at: https://creativecommons.org/licenses/by-nc-nd/4.0/

\section{LICENCE}

CC BY-NC-ND 4.0

\section{REPOSITORY RECORD}

Amir, Ziv, A. Popa, S. Tamminga, D. Yagil, Fehmidah Munir, and A. de Boer. 2019. "Employer's Management of Employees Affected by Cancer". figshare. https://hdl.handle.net/2134/27932. 


\section{Employer's management of employees affected by cancer}

Z. Amir ${ }^{1}$ \& A. Popa ${ }^{2}$ \& S. Tamminga ${ }^{3}$ \& D. Yagil ${ }^{4}$ \& F. Munir ${ }^{5}$ \& A. de Boer ${ }^{3}$

Published in: Cancer Supportive Care

https://doi.org/10.1007/s00520-017-3998-8

Accepted: 24 November 2017

Correspondence:

Z. Amir

z.amir@salford.ac.uk

1 School of Health Sciences, Salford University, Greater

Manchester, UK

2 Department of Journalism Public Relations, Sibiu University,

Sibiu, Romania

3 Coronel Institute of Occupational Health, AMC,

Amsterdam, Netherlands

4 Department of Human Services, University of Haifa, Haifa, Israel

5 School of Sport, Exercise \& Health Sciences, Loughborough

University, Loughborough, UK 


\section{Employer's management of employees affected by cancer}

\section{Introduction:}

Return to work (RTW) following treatment can be problematic for cancer survivors. Although some people affected by cancer are able to continue working, a significant proportion of these survivors end up unemployed, retire early or change jobs more often than those without a diagnosis of cancer (1). One of the reasons for not returning to work is the lack of understanding and support from employers and supervisors (2). Currently, it is not clear what factors are likely to influence the employer's management of employees recovering from cancer. This article reports the outcome from a review of published literature on factors related to the current employer management of employed cancer survivors.

\section{Method:}

The conducted in-depth review (scientific literature from 1980 to 2016) used the National Institute for Health and Care Excellence evidence based systematic review guidelines (3). Articles were identified using PubMed, Google Scholar, Web of Science, Science Direct, Embase, PsychInfo and Cochrane Central Register of Controlled Trials. Inclusion criteria were: 1) original empirical articles; 2) data on supervisors and/or employers of return to work after a cancer diagnosis; 3 ) data on supervisors and/or employers from the employer and/or employee perspective; 4) articles focusing on adult cancer patients; 5) written in English; and 6) where access to full article was available. Results were synthesized according to the Resource Dependence Institutional Cooperation Model (RDIC) model (4). 


\section{Results:}

Twenty-six papers have been identified including 11 from the Europe; 4 from Asia; 6 from USA and 5 from Australia of which 16 were mainly qualitative studies and 10 were quantitative studies (5-30). Review of these papers provided insight into the range and complexity of factors that influence an employer's management of employees diagnosed and treated for cancer; which have been synthesized according to the RDIC model (Figure 1)

Employers' perception and/or implementation of their organisation's RTW policies:

As with other chronic health problems in the workplace, RTW policies were crucial for supervisor or employer_to support the RTW of employees following cancer treatment. $(10,20,23)$. Yet in many organisations, RTW policies were not available and for most organisations, practices and procedures for managing RTW following cancer are not uniform or specific to cancer (19). Organisations that did not have explicit RTW policies $(19,30)$ often had poor lines of communication between the supervisor or employer_and the employee and between the manager and other stakeholders involved in the RTW process (e.g. occupational health). This lack of guidance available to supervisors and employers_on how to conduct a RTW for employees reduced the process to 'trial and error' format. As a result, supervisors and employers were reluctant to proactively contact their employees and instead would defer to 'second hand' information channels to keep themselves informed about their employees. These types of practices increased the risk of employees experiencing distress when their return to work was being managed (19). 
Whilst the studies reviewed here have been conducted in different countries with different healthcare and social systems, they similarly report that the way supervisors or employers implemented workplace RTW policies depended on how clear such policies were. This suggests that there is currently much variation within organisations in how RTW is managed for employees returning from sick leave for cancer treatment.

A UK study (7) reported that managers held favourable attitudes towards enabling employees with cancer to maintain normalcy and supporting them in the process of RTW. Despite these positive attitudes, some managers perceived the requirement to make appropriate work accommodations for cancer survivors as a burden and they harboured negative attitudes regarding the individual's ability to work and meet the demands of the job $(7,12)$.

\section{Employees' perception of their employer's role and support:}

The evidence for employees' perception of their employer's role and support is variable. Some studies reported positive perceived employer support for cancer survivors $(13,18,26)$ while others highlighted perceived discrimination and low levels of management support $(23,25,28)$.

It may well be that the conflicting evidence is related to the existence of relevant policies applicable to individuals with a history of cancer (16), different levels of employee expectations and type of cancer and/or the cancer treatment received $(27,28)$.

However, a good relationship with the supervisor or employer_was a major factor perceived by employees as influencing RTW after cancer treatment $(5,19,20)$. Employees expressed this relationship as a "contract" between the employee and the employer, which consisted of mutual respect, compassion and effective communication (19). This set of expectations or 
"contract" was based on the duration of service prior to the cancer diagnosis (5) and was strongly perceived by employees as contributing to long-term employment following cancer treatment (18).

\section{Conclusion:}

Demand-side employment research is emerging as an important line of employment and disability research. One emphasis of this line of research is to examine the perceptions of chronic illness and disability (e.g. cancer) from the employer perspective.

There is a strong need for more comprehensive studies that are methodologically sound and that build on many of the qualitative studies reported here. There is little available evidence as to how employer management and support of cancer survivors impacts on their ability to RTW.

Furthermore, our review found no intervention studies related to the effectiveness of employer management. Intervention studies could explore the feasibility and/or effectiveness of various interventions of employer management and support of cancer survivors. Interventions should include the use of explicit workplace RTW policies, and employer training on managing a successful return to work/work retention. Furthermore, specific cancer survivor-related accommodations and education on the impact of employers' perceptions of employee characteristics on poor RTW outcomes are important components which need to be included in any interventions. Results from these interventions will enable those cancer survivors who wish to continue to work to achieve this goal which is important for their quality of life.

\section{References:}


1. De Boer, A. G., Taskila, T., Ojajärvi, A., van Dijk, F. J., \& Verbeek, J. H. (2009). Cancer survivors and unemployment: a meta-analysis and meta-regression. Jama, 301(7), 753-762.

2. Tiedtke, C., Dierckx de Casterlé, B., Donceel, P., \& de Rijk, A. (2015). Workplace support after breast cancer treatment: recognition of vulnerability. Disability and rehabilitation, 37(19), 1770-1776.

3. National Institute for Health and Care Excellence (NICE) (2012). Methods for the development of NICE public health guidance (third edition). Accessed from: http://publications.nice.org.uk/methods-for-the-development-of-nice-public-healthguidance-third-edition-pmg4/determining-the-evidence-for-review-andconsideration\#CPHE-correlates-reviews).

4. de Rijk, A., van Raak, A., \& van der Made, J., (2007), A new theoretical model for cooperation in public health settings: the RDIC model. Quality in Health Research, $17,1103-1116$.

5. Amir, Z., Neary, D., \& Luker, K. (2008). Cancer survivors' views of work 3 years post diagnosis: a UK perspective. European Journal of Oncology Nursing, 12(3), 190-197.

6. Amir, Z., Wynn, P., Whitaker, S., \& Luker, K. (2009). Cancer survivorship and return to work: UK occupational physician experience. Occupational medicine, 59(6), 390-396.

7. Amir, Z., Wynn, P., Chan, F., Strauser, D., Whitaker, S., \& Luker, K. (2010). Return to work after cancer in the UK: attitudes and experiences of line managers. Journal of occupational rehabilitation, 20(4), 435-442.

8. Ashing-Giwa, K. T., Padilla, G., Tejero, J., Kraemer, J., Wright, K., Coscarelli, A., \& Hills, D. (2004). Understanding the breast cancer experience of women: a qualitative study 
of African American, Asian American, Latina and Caucasian cancer survivors. PsychoOncology, 13(6), 408-428.

9. Blinder, V. S., Murphy, M. M., Vahdat, L. T., Gold, H. T., de Melo-Martin, I., Hayes, M. K., \& Mazumdar, M. (2012). Employment after a breast cancer diagnosis: a qualitative study of ethnically diverse urban women. Journal of community health, 37(4), 763-772.

10. Eguchi, H., Wada, K., Higuchi, Y., \& Smith, D. R. (2017). Co-worker perceptions of return-to-work opportunities for Japanese cancer survivors. Psycho-Oncology, 26, 309-315.

11. Ehrmann-Feldmann, D., Spitzer, W. O., Del Greco, L., \& Desmeules, L. (1987). Perceived discrimination against cured cancer patients in the work force. CMAJ: Canadian Medical Association Journal, 136(7), 719.

12. Grunfeld, E. A., Low, E., \& Cooper, A. F. (2010). Cancer survivors' and employers' perceptions of working following cancer treatment. Occupational medicine, 60(8), 611-617.

13. Lindbohm, M. L., Taskila, T., Kuosma, E., Hietanen, P., Carlsen, K., Gudbergsson, S., \& Gunnarsdottir, H. (2012). Work ability of survivors of breast, prostate, and testicular cancer in Nordic countries: a NOCWO study. Journal of Cancer Survivorship, 6(1), 7281.

14. Luker, K., Campbell, M., Amir, Z., \& Davies, L. (2013). A UK survey of the impact of cancer on employment. Occupational medicine, 63(7), 494-500. 
15. Main, C. J., \& Shaw, W. S. (2016). Employer Policies and Practices to Manage and Prevent Disability: Conclusion to the Special Issue. Journal of Occupational Rehabilitation, 26(4), 490-498.

16. Mak, A. K. Y., Chaidaroon, S., Fan, G., \& Thalib, F. (2014). Unintended consequences: the social context of cancer survivors and work. Journal of Cancer Survivorship, 8(2), 269-281.

17. Mak, A. K. Y., Ho, S. S., \& Kim, H. J. (2014). Factors related to employers' intent to hire, retain and accommodate cancer survivors: The Singapore perspective. Journal of occupational rehabilitation, 24(4), 725-731.

18. McGrath, P. D., Hartigan, B., Holewa, H., \& Skarparis, M. (2012). Returning to work after treatment for haematological cancer: findings from Australia. Supportive Care in Cancer, 20(9), 1957-1964.

19. McKay, G., Knott, V., \& Delfabbro, P. (2013). Return to work and cancer: the Australian experience. Journal of occupational rehabilitation, 23(1), 93-105.

20. Poulsen, M. G., Khan, A., Poulsen, E. E., Khan, S. R., \& Poulsen, A. A. (2016). Work engagement in cancer care: The power of co-worker and supervisor support. European Journal Oncology Nursing, 21(21), 134-138.

21. Pransky, G. S., Fassier, J. B., Besen, E., Blanck, P., Ekberg, K., Feuerstein, M., Hopkinton Conference Working Group on Workplace Disability, P. (2016). Sustaining Work Participation Across the Life Course. Journal of Occupational Rehabilitation, 26(4), 465-479.

22. Selander, J., Tjulin, Å., Müssener, U., \& Ekberg, K. (2015). Contact With the Workplace During Long-Term Sickness Absence and Worker Expectations of Return 
to Work. International Journal of Disability Management Research, 10, 13. doi:http://dx.doi.org/10.1017/idm.2015.3

23. Stergiou-Kita, M., Pritlove, C., \& Kirsh, B. (2016). The "Big C"-stigma, cancer, and workplace discrimination. Journal Cancer Survivorship, 10(6), 1035-1050. doi:10.1007/s11764-016-0547-2

24. Stergiou-Kita, M., Pritlove, C., van Eerd, D., Holness, L. D., Kirsh, B., Duncan, A., \& Jones, J. (2016). The provision of workplace accommodations following cancer: survivor, provider, and employer perspectives. Journal Cancer Survivorship, 10(3), 489-504. doi:10.1007/s11764-015-0492-5

25. Stewart, D. E., Cheung, A. M., Duff, S., Wong, F., McQuestion, M., Cheng, T., \& Bunston, T. (2001). Long-term breast cancer survivors: confidentiality, disclosure, effects on work and insurance. Psycho-Oncology, 10(3), 259-263.

26. Tan, F. L., Loh, S. Y., Su, T., Veloo, V. W., \& Ng, L. L. (2012). Return to work in multiethnic breast cancer survivors-a qualitative inquiry. Asian Pacific Journal of Cancer Prevention, 13(11), 5791-5797.

27. Tamminga, S. J., De Boer, A. G., Verbeek, J. H., \& Frings-Dresen, M. H. (2012). Breast cancer survivors' views of factors that influence the return-to-work process-a qualitative study. Scandinavian journal of work, environment \& health, 144-154.

28. Taskila, T., Lindbohm, M. L., Martikainen, R., Lehto, U. S., Hakanen, J., \& Hietanen, P. (2006). Cancer survivors' received and needed social support from their work place and the occupational health services. Supportive Care in Cancer, 14(5), 427-435. 
29. Tiedtke, C., Donceel, P., De Rijk, A., \& De Casterlé, B. D. (2014). Return to work following breast cancer treatment: the employers' side. Journal of occupational rehabilitation, 24(3), 399-409.

30. Yarker, J., Munir, F., Bains, M., Kalawsky, K., \& Haslam, C. (2010). The role of communication and support in return to work following cancer-related absence. Psycho-Oncology, 19(10), 1078-1085. 


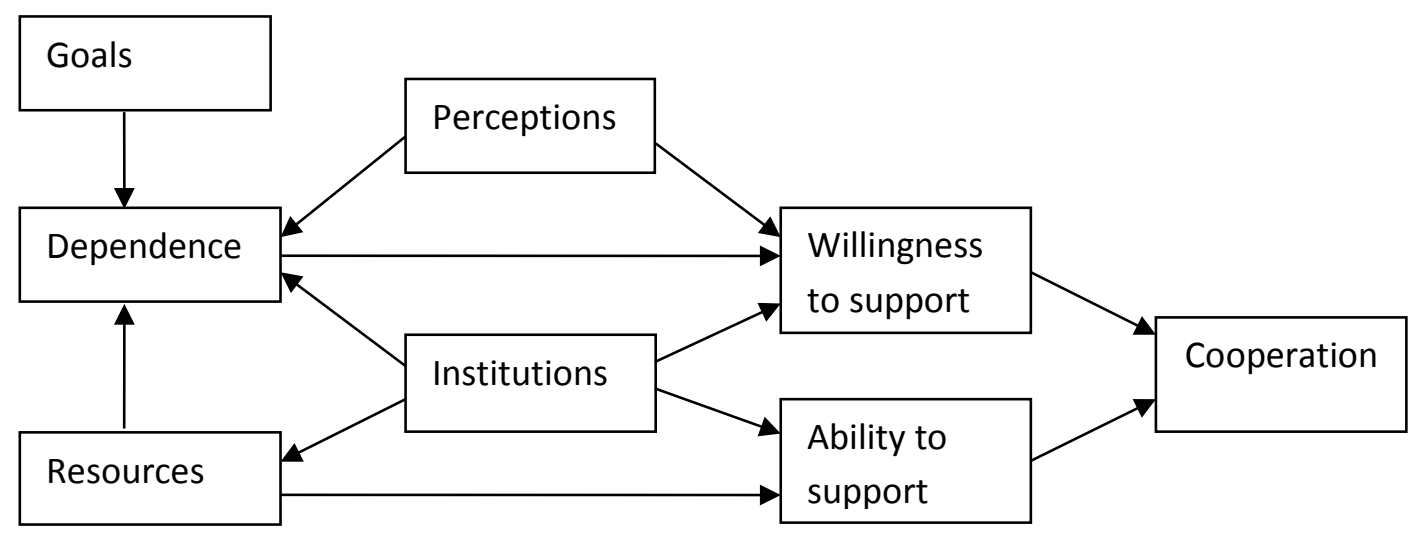

Figure 1: Factors synthesized according to the Resource Dependence Institutional Cooperation Model (RDIC) model of de Rijk et al.2007 (4). Note that goals, dependency, resources, perceptions, and institutions lead to a degree of willingness and ability to support which in turn leads to amount of cooperation.

Employer-related factors that influence an employer's management of employees diagnosed and treated for cancer:

Goals: none found in this review.

Dependence: The psychological contract between employer and employee was found to be important for receiving good return to work management and support; Some workers who disclosed their diagnoses to their employer received support, but some expressed discomfort in their supervisor or coworkers finding out about their diagnosis; Defer to 'second hand' information channels to keep themselves informed.

Resources: Lack of guidance to managers; Managers have a lack of knowledge in how to best respond; Employees' incapability to effectively communicate with their supervisor about RTW issues; Supervisors should be provided the skills to promote good communication and leadership to support all workers and to provide an environment that promotes a strong, supportive work culture.

Perceptions: Reluctant to proactively contact their employee with cancer; enabling employees with cancer to maintain normalcy; Negative attitudes regarding the individual's ability to work and meet the demands of the job; Favourable attitude in supporting them in the process of RTW; Perceived appropriate work accommodations for cancer survivors as a burden; Professional rather than nonprofessional position influenced employer's perceptions of employee characteristics; Negative attitudes toward employee's work ability; Duration of service rather than occupation played a role with the relationship with the employer; Beliefs that cancer treatment will impair work ability; More negative beliefs than cancer patients on the impact of cancer treatment on work; Avoidance behaviour from supervisors led to poor work ability among employees recovering from cancer; Perception of employer's obligations to provide support; Perception of employee' work ability; Employer's confidence in organisational culture and resources; Perceptions of overprotection leading to underestimation of employee's capability; Employer's own personal views and experiences influenced their management of employees recovering from cancer; Beliefs and values of leadership often overpower evidence-based practice; Importance of a shift in focus from the medical aspects of illness tot functional ability of the employee, with employers and supervisors as natural collaborators 
in the return-to-work process; Supervisors and co-workers should be aware that they play a significant role in the return to work process and that quality of contact is what matters

Institution: Absence of RTW policies; Practices and procedures not specific to cancer; No clear policies; Way polices were implemented; Late implementation of organisational guidelines and/or policies; Lack of Flexible work policy; Return to work protocols enabled managers to return employees to work; Organizational decision-making is often influenced by a crisis or in response to market factors of legal requirements

Cooperation: Poor lines of communication between employee and employer and between employer and other relevant stakeholders; Discrimination; Lack of communication; Low level of management support; Positive employer support; Good relationship between employer and employee with cancer consisted of compassion, respect and effective communication; Few employer management differences reported between ethnic groups; Cancer survivors with poor prognosis experienced slightly more discrimination than subjects with better prognosis; Employees perceived good support from their employers during sickness absence and initial return to work; Employees perceived different levels of discrimination from their employers; Employees perceived good tangible and psychological support from their employers during sickness absence and initial return to work; Perceptions of discrimination left women feeling they were unable to reach their full job potential; Tangible support from employer aided employee return to work; Stigma and workplace discrimination are significant concerns for cancer survivors; Ongoing communication and monitoring are required to ensure accommodations. 